\title{
Avaliação de polventes do ar em áreas de recreação urbana da cidade de Fortaleza
}

\author{
Assessment of air pollutants in urban recreation areas of Fortaleza city
}

Mona Lisa Moura de Oliveira[a] (b), Mauro Henrique Porfírio Sampaio Lopes[a], Nara Angélica Policarpo [b], Camila Maria Aguiar da Costa Alves[c] $[$, Rinaldo dos Santos Araújo[d], Francisco Sales Ávila Cavalcante[a]

\author{
[a] Universidade Estadual do Ceará (UECE), Fortaleza, CE, Brasil \\ [b] Universidade Estadual de Campinas (UNICAMP), Campinas, SP, Brasil \\ [c] Universidade Federal de Santa Maria (UFSM), Santa Maria, RS, Brasil \\ [d] Instituto Federal do Ceará (IFCE), Fortaleza, CE, Brasil
}

Como citar: Oliveira, M. L. M., Lopes, M. H. P. S., Policarpo, N. A., Alves, C. M. A. C., Araújo, R. S., \& Cavalcante, F. S. A. (2019). Avaliação de poluentes do ar em áreas de recreação urbana da cidade de Fortaleza. urbe. Revista Brasileira de Gestão Urbana, 11, e20180187. https://doi.org/10.1590/2175-3369.011.e20180187

\section{Resumo}

O crescimento urbano desorganizado tem gerado muitos problemas em grandes centros urbanos, sobretudo reduzindo o conforto ambiental da população local. A administração pública está cada vez mais procurando mitigar esses efeitos, melhorando a qualidade de vida da população por meio de um modelo de gestão mais sustentável, com ações de implantação de Ambientes Urbanos Desportivos (AUDs). A cidade de Fortaleza, no Ceará, é a quinta maior capital da federação em termos de quantidade populacional. Além disso, possui uma frota de mais de 1 milhão de veículos em circulação. Os AUDs foram instalados em muitos bairros da cidade com o objetivo de oferecer áreas de lazer e recreação para a população local. Contudo, a qualidade do ar nessas áreas ainda é desconhecida por causa da ausência de ações de monitoramento, especialmente durante uma intensa prática de atividade física. Este trabalho tem como objetivo monitorar espécies atmosféricas, $\mathrm{NO}_{2}, \mathrm{NH}_{3}, \mathrm{SO}_{2}$ e $\mathrm{H}_{2} \mathrm{~S}$, em 13 AUDs (diferentes bairros da cidade de Fortaleza) utilizando sistemas portáteis. Os resultados mostraram que as concentrações de gases detectados nos dias monitorados foram (em $\mu \mathrm{g} . \mathrm{m}^{-3}$ ): de 2,58 a 18,48 de $\mathrm{NO}_{2}$; de 0,18 a 3,36 de $\mathrm{SO}_{2}$; de 2,78 a 11,07 de $\mathrm{NH}_{3}$; e de 0,76 a 7,53 de $\mathrm{H}_{2} \mathrm{~S}$. Reduções significativas das concentrações de $\mathrm{NO}_{2}(41 \%)$ e $\mathrm{NH}_{3}(\sim 60 \%)$ foram observadas nos finais de semana, como resultado da diminuição do tráfego veicular. Além disso, o monitoramento da qualidade do ar nos AUDs pode sugerir e/ou apoiar políticas públicas para controlar a poluição do ar na cidade de Fortaleza.

Palavras-chave: Poluição atmosférica. Monitoramento. Ambiente urbano.

MLMO é doutora em Engenharia Mecânica, e-mail: mona.lisa@uece.br

MHPSL é mestre em Ciências Físicas Aplicadas, e-mail: maurosampaio16@hotmail.com

NAP é doutora em Engenharia de Petróleo, e-mail: npolicarpo@yahoo.com

CMACA é graduada em Licenciatura em Química, mestranda de Química Analítica, e-mail: camilamacalves@gmail.com

RSA é doutor em Química, e-mail: rinaldoifce@gmail.com

FSAC é doutor em Física, e-mail: sales.avila@uece.br 


\section{Abstract}

Disorganized urban growth has generated many problems in large urban centers, especially reducing the environmental comfort of the local population. Public administration is increasingly searching to mitigating these problems and improving the population quality of life through sustainable management, as the input of Urban Recreation Areas (URA). Fortaleza city is $5^{\circ}$ largest federation capital, in population amount. It has a fleet of more than 1 million vehicles. URAs have been installed in many Fortaleza city's zone, aiming to offer leisure and recreation areas to the local population. Air quality in these URA is unknown due to the monitoring actions is a deficiency, essentially during a physical activity local. This work aims to monitor atmospheric species, $\mathrm{NO}_{2}, \mathrm{NH}_{3}, \mathrm{SO}_{2}$, and $\mathrm{H}_{2} \mathrm{~S}$, in the 13 URA (different zone) using the typical portable system. Results showed that the concentrations of gases detected in the monitored days were ( $\mu \mathrm{g} . \mathrm{m}^{-3}$ ): 2.58-18.48 of $\mathrm{NO}_{2}$; 0.18-3.36 of $\mathrm{SO}_{2}$; 2.78-11.07 of $\mathrm{NH}_{3}$, and 0.76-7.53 of $\mathrm{H}_{2} \mathrm{~S}$. Significant reductions of $\mathrm{NO}_{2}$ (41\%) and $\mathrm{NH}_{3}$ (60\%) concentrations were observed at the weekends as a result of vehicular traffic reduction. Also, the monitoring of air quality in URA may suggest and/or support public policies to control the air pollution of Fortaleza city.

Keywords: Atmospheric pollution. Monitoring. Urban environment.

\section{Introdução}

Frequentemente, a poluição atmosférica tem se tornado um problema comum nos grandes centros urbanos, porém desconhece-se o seu real impacto à saúde. A poluição do ar tem sido responsável por cerca de 3 milhões de mortes prematuras no mundo a cada ano, das quais mais da metade ocorre em países em desenvolvimento (WHO, 2010; Li et al., 2014). De fato, processos de urbanização acarretam uma série de mudanças no estilo de vida das pessoas, criando hábitos que modificam drasticamente o ambiente e o clima e, consequentemente, desencadeiam impactos sobre a saúde em todos os seus aspectos (Manes et al., 2008; Fu et al., 2013; Mohamed \& Othman, 2012; Vormittag et al., 2014).

A frota veicular em centros urbanos aumentou exponencialmente nos últimos anos, e isso é um dos principais motivos para o aumento da poluição atmosférica nessas regiões; assim, torna-se cada vez mais importante a busca de soluções para mitigar essas consequências (Mitra et al., 2002; Campos et al., 2010; Righi et al., 2013; Azevedo, 2014; CETESB, 2014; COP21, 2015; Papamanolis, 2015).

Desse modo, as gestões públicas de grandes centros urbanos vêm buscando meios de reduzir os problemas ambientais e melhorar a qualidade de vida da população com um formato de gestão mais sustentável (Manes et al., 2008; Mohamed \& Othman, 2012; Eime et al., 2015). Uma das ações promovidas está na implantação de Ambientes Urbanos Desportivos (AUDs), muitos deles contando com equipamentos para prática de atividade física. Essas necessidades são supridas por meio do planejamento urbano, visando melhorar a qualidade de vida das pessoas (Mohamed \& Othman, 2012; Costa et al., 2015; Węziak-Białowolska, 2016). Contudo, dependendo da localização desses equipamentos, poderá afetar positiva ou negativamente o bem-estar e a saúde das populações (Dahmann et al., 2010; Cárdenas Rodríguez et al., 2016).

A cidade de Fortaleza, que está localizada no Estado do Ceará, região Nordeste do país, e possui a quinta maior capital em termos de população, com mais de 2 milhões de habitantes (IBGE, 2016), conta com uma frota de mais de 1 milhão de veículos automotores (DETRAN-CE, 2017; Policarpo et al., 2018), sendo que, até 2011, a mobilidade no Brasil era caracterizada por uma frota de 33 milhões de veículos, com um índice de motorização de 288 veículos/1.000 habitantes (IBGE, 2016; Urban Leds, 2016).

Em Fortaleza, os AUDs vêm se tornando cada vez mais frequentes em diferentes regiões, fazendo com que a atividade física passe a ser um elemento da vida e da cultura da comunidade. Entretanto, o monitoramento da qualidade do ar ainda é deficiente, e não se sabe quais as características do ar que se respira, muito menos nas áreas de lazer e recreação, especialmente durante a prática intensiva de atividade física em tais locais (Van den Bossche et al., 2015). 
Desde 2007, oficialmente, nenhum monitoramento da qualidade do ar no município de Fortaleza tem sido reportado pelos órgãos ambientais locais, apesar da grande quantidade de veículos em circulação e das centenas de indústrias potencialmente poluidoras distribuídas no território municipal e na região metropolitana. Contudo, diversos trabalhos vêm sendo reportados na comunidade científica, porém é ainda incipiente quando se trata de um monitoramento contínuo e/ou até mesmo com maior amplitude nas zonas de cobertura do presente trabalho (Day et al., 2012; Liu et al., 2014; COP21, 2015).

Os óxidos de nitrogênio $\left(\mathrm{NO}_{\mathrm{x}}\right)$, dióxido de enxofre $\left(\mathrm{SO}_{2}\right)$ e compostos orgânicos voláteis (COV) são potenciais poluentes atmosféricos responsáveis por várias reações fotoquímicas e processos físicos na atmosfera, ocasionando diversas consequências, como formação de ozônio troposférico, de partículas secundárias e de deposição (Campos et al., 2010; Kourtidis et al., 2008). A amônia atmosférica tem sido reconhecida como um importante poluente do ar e contribuinte da eutrofização e da acidificação dos ecossistemas (Sheppard et al., 2011). Infelizmente, até o momento, a amônia $\left(\mathrm{NH}_{3}\right)$ e o sulfeto de hidrogênio $\left(\mathrm{H}_{2} \mathrm{~S}\right)$ não estão incluídos como espécies nos padrões de qualidade do ar no Brasil (Brasil, 1990). A amônia, em ambientes não agrícolas, pode ser originada por meio de diversas fontes de emissão, tais como tráfego rodoviário, sistemas de refrigeração, atividade industrial, aterro sanitário, entre outras (Sheppard et al., 2011; Day et al., 2012; Reche et al., 2015). Problemas relacionados a odores também têm sido frequentemente relatados. $\mathrm{O} \mathrm{H}_{2} \mathrm{~S}$, por exemplo, apresenta odor muito desagradável, que é perceptível ao sentido humano em pequenas concentrações, ocasionando mau cheiro próximo das fontes emissoras (Campos et al., 2010). $\mathrm{O} \mathrm{H}_{2} \mathrm{~S}$ e os tiocompostos orgânicos podem ser originados na decomposição anaeróbica de poluentes presentes na água e são potenciais poluentes atmosféricos, podendo ocasionar danos à saúde, como afetar o sistema respiratório e o sistema nervoso, dependendo de sua concentração (Muezzinoglu, 2003; Wang \& Zhang, 2014; Wang et al., 2015).

Em geral, a qualidade do ar possui influência e dependência de alguns aspectos: (i) quantidade de poluentes emitidos de qualquer substância que torne o ar impróprio, nocivo ou ofensivo à saúde e ao ecossistema; (ii) capacidade de dispersão do ambiente; (iii) fenômenos meteorológicos; e (iv) topografia da região. Dessa forma, as medições de gases atmosféricos são muito importantes para o monitoramento da qualidade do ar e, consequentemente, para a saúde pública da comunidade local.

Destaca-se ainda que o sistema respiratório humano é especialmente sensível ao impacto das emissões veiculares, causando modificações patológicas no sistema broncopulmonar, promovendo o aumento da morbidade geral (Sheppard et al., 2011). É de conhecimento que o exercício físico aumenta o volume de ar inspirado, e, em alguns casos, esse volume passa de 6 a 10 litros (em repouso) para 100 a 150 litros (em atividade). Em ambientes poluídos, espécies poluentes presentes no ar são fortes oxidantes, isto é, aumentam os radicais livres no organismo e causam, entre outros problemas, o envelhecimento celular precoce (Checa Vizcaíno et al., 2016).

Desse modo, quanto mais se realiza exercícios físicos, mais se necessita de oxigênio, e com ele vêm os poluentes atmosféricos que diminuem a capacidade respiratória (Rundell, 2012; Roberts et al., 2014; ERS\&ELF, 2015). Assim, o presente estudo tem como objetivo principal determinar concentrações de gases traços presentes na atmosfera de áreas de recreação (AUDs) da cidade de Fortaleza, nomeadamente $\mathrm{NO}_{2}, \mathrm{NH}_{3}, \mathrm{SO}_{2}$ e $\mathrm{H}_{2} \mathrm{~S}$. Espera-se também estabelecer índices de qualidade do ar local para esses ambientes monitorados, apresentando sua presença no ar durante a prática de atividade física e contribuindo para gestão pública na elaboração de um histórico de monitoramento da qualidade do ar na cidade de Fortaleza em áreas de recreação e lazer (WHO, 1981; Chong et al., 2016). 


\section{Metodologia}

\section{Caracterização dos Ambientes Urbanos Desportivos (AUDs)}

O presente estudo foi realizado em diferentes regiões da cidade de Fortaleza, no Ceará, com o propósito de abranger ambientes urbanos nos quais os cidadãos praticam atividades físicas e/ou de recreação quando desfrutam do lazer. A cidade de Fortaleza, desde 1997, por meio da Lei Municipal no 8.000/1997, foi dividida em subdivisões regionais, as Secretarias Executivas Regionais (SER), com o intuito de descentralizar o poder do gestor principal da cidade de Fortaleza e criar uma intersetorialidade municipal, tentando solucionar as demandas de cada bairro com maior proximidade e efetividade à comunidade. Existem sete Secretarias Executivas Regionais no município (Batista et al., 2005), e este estudo monitorou pelo menos um AUD em cada uma dessas regiões. Cada AUD monitorado pode ser observado na Figura 1. Foram selecionados ambientes sob intensa ou quase inexistente influência de tráfego veicular, nos quais a comunidade local realiza práticas frequentes de exercícios físicos ao ar livre. Os AUDs próximos às áreas litorâneas, às estações de tratamento de esgoto, aos sumidouros, entre outras, também foram considerados no presente estudo.

(a)
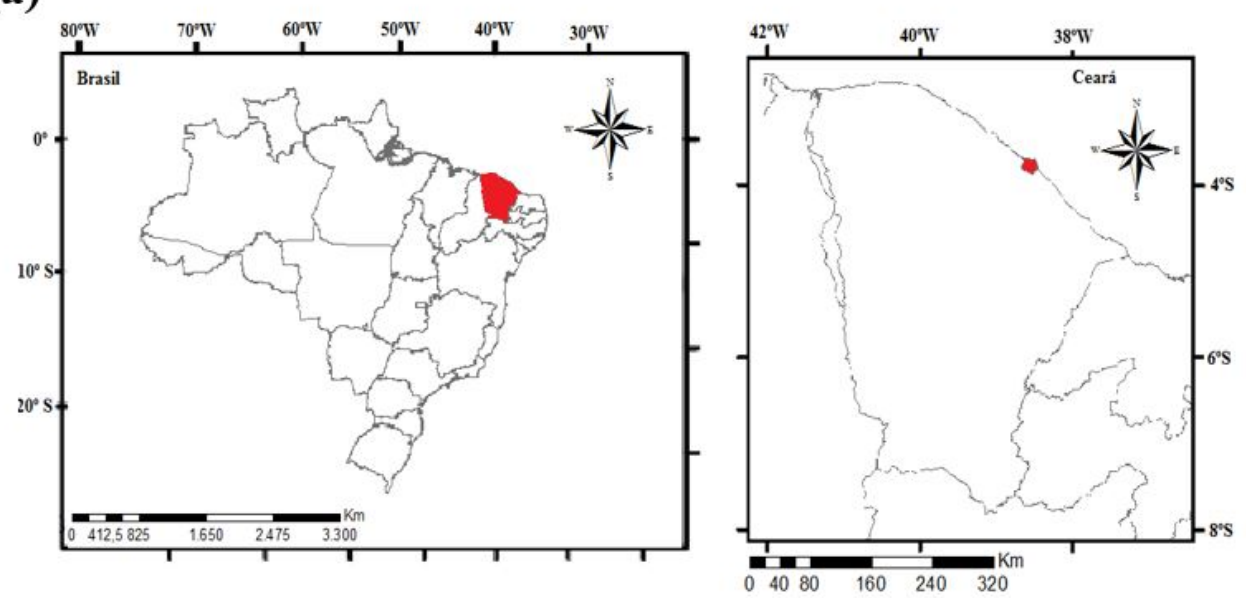

(b)

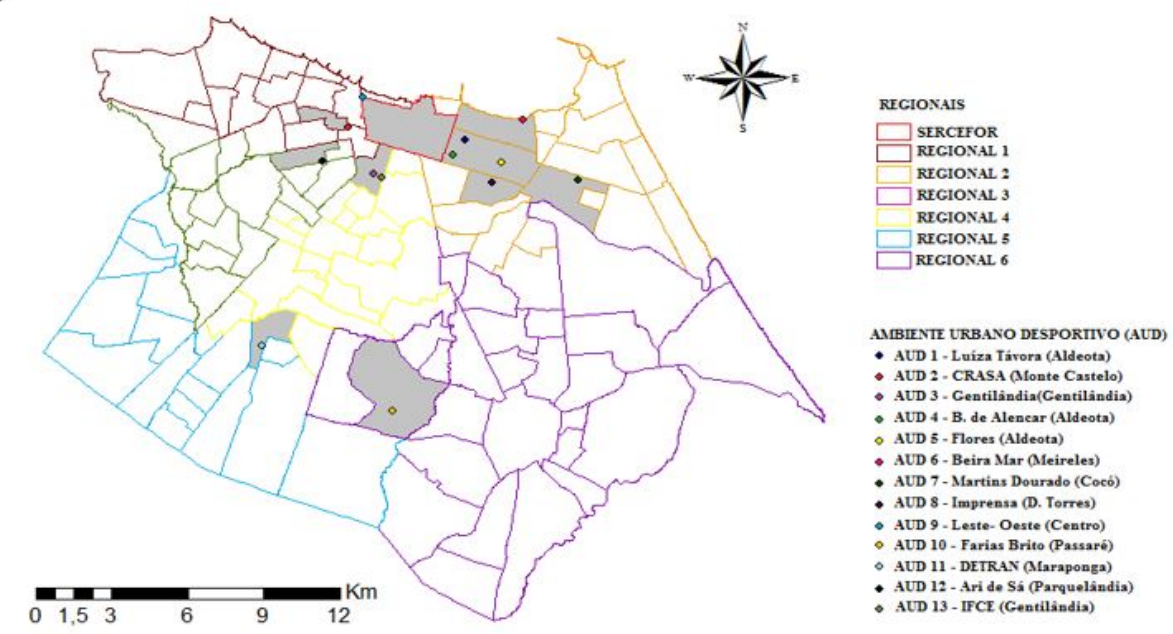

Figura 1 - Mapas: (a) cidade de Fortaleza; e (b) AUDs monitorados. Fonte: Adaptada de Batista et al. (2005). 


\section{Aquisição de dados meteorológicos dos AUDs}

Para obtenção dos dados meteorológicos, foi utilizada uma estação meteorológica portátil da Davis Instruments, modelo Vantage Vue (Davis Instruments, 2015). As principais variáveis meteorológicas, como temperatura, umidade relativa, precipitação, velocidade dos ventos, direção dos ventos e pressão atmosférica, foram simultaneamente registradas em tempo real. A aquisição de dados foi realizada por meio de um sistema com transmissão de dados via wireless, podendo alcançar até 300 m de distância do equipamento.

\section{Amostragem e análises}

Foram adaptados quatro Amostradores de Pequeno Volume (APV) do tipo MONOGÁS (Uso individual por espécie), a partir do TRIGAS (Energética Ind. Com. Ltda.), para a coleta de $\mathrm{SO}_{2}, \mathrm{NO}_{2}, \mathrm{H}_{2} \mathrm{~S}$ e $\mathrm{NH}_{3}$, compostos de frasco borbulhador de $150 \mathrm{ml}$, para solução absorvedora seletiva da espécie de interesse, gasômetro e bomba de sucção do ar, usados nos AUDs em estudo. As recomendações da USEPA (1998; USEPA, 2007) foram seguidas quanto à localização e à altura dos APV, com entrada de ar posicionada a 2 m do solo, conforme exemplificados na Figura 2.

(a)

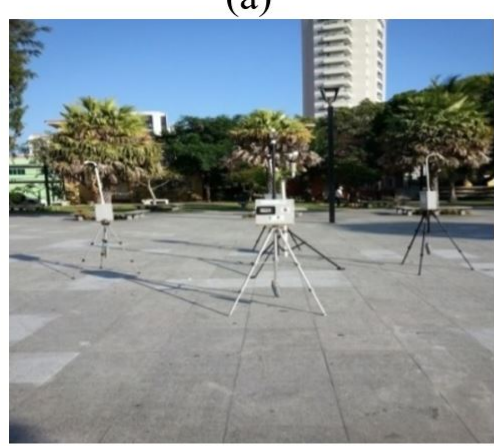

(d)

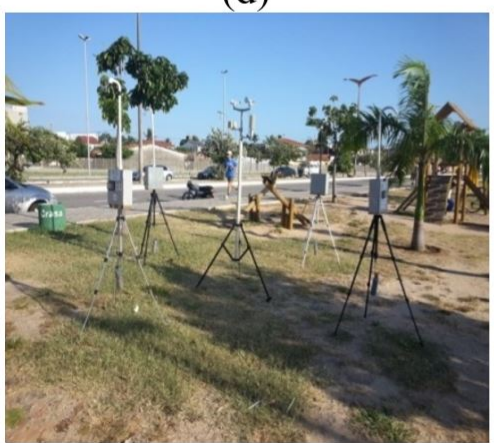

(b)

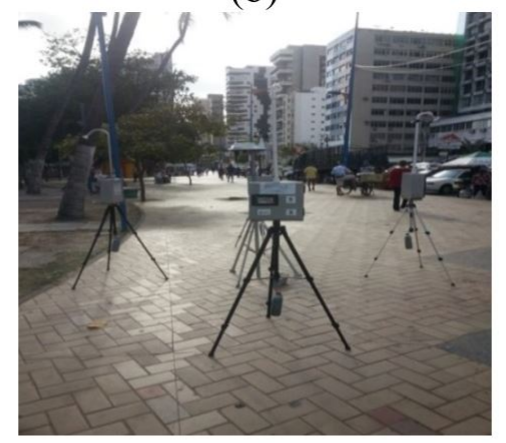

(e)

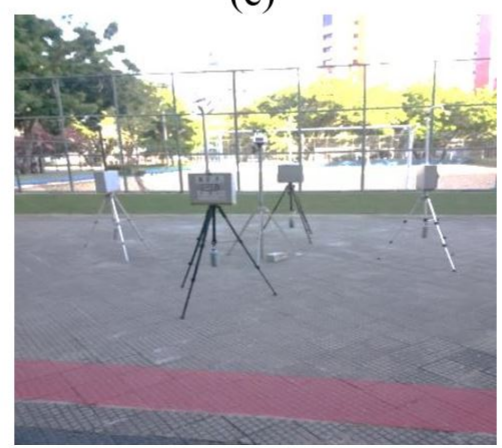

(c)

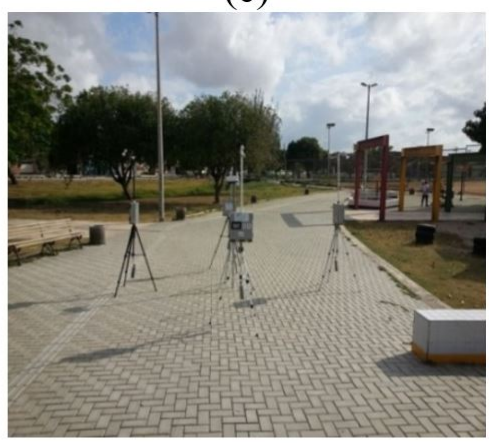

(f)

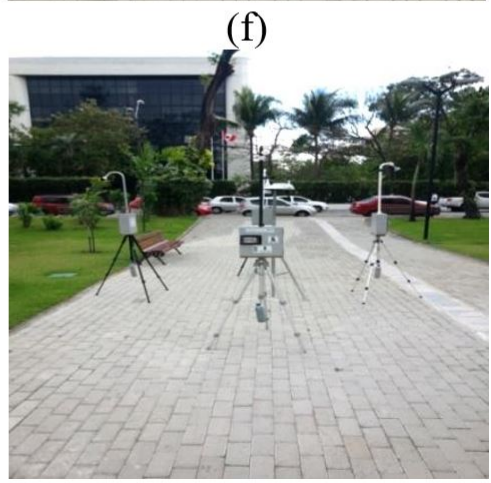

Figura 2 - Exemplos dos APV dispostos nos AUDs avaliados: (a) Praça Luiza Távora - AUD 1; (b) Beira Mar AUD 6; (c) Praça Farias Brito - AUD 10; (d) Calçadão CRASA - AUD 2; (e) Praça Martins Dourado - AUD 7;

(f) Praça da Imprensa - AUD 8. Fonte: Autor (2016).

O monitoramento ocorreu no ano-base de 2015, entre os meses de agosto e outubro, na cidade de Fortaleza, totalizando 13 semanas seguidas de monitoramento e análise de gases traços dos AUDs. Foi definida a vazão de $2 \mathrm{l} /$ min para os dispositivos que coletavam $\mathrm{NO}_{2}, \mathrm{H}_{2} \mathrm{~S}$ e $\mathrm{NH}_{3}$. No sistema de coleta de $\mathrm{H}_{2} \mathrm{~S}$, a vazão foi definida em $1,3 \mathrm{l} / \mathrm{min}$.

Cada espécie foi monitorada nos ambientes (AUDs) selecionados por meio de métodos indiretos, utilizando um espectrofotômetro UV-Visível da Thermo Scientific Genesys $10 \mathrm{~S}$.

As respectivas metodologias analíticas estão descritas a seguir: (i) $\mathrm{NO}_{2}$ foi determinado por meio do método do arsenito de sódio (USEPA, 1977); (ii) $\mathrm{SO}_{2}$, pelo método da pararosanilina, segundo a USEPA 
EQS-0775-002/1975 (USEPA, 1977); (iii) $\mathrm{NH}_{3}$, mediante o método do indofenol (Lodge, 1989; Reche et al., 2015); e (iv) $\mathrm{H}_{2} \mathrm{~S}$, por intermédio do método do azul de metileno (Delgado et al., 1999). No presente trabalho, o fluxo típico de veículos ao redor dos AUDs monitorados também foi considerado. Em dias úteis, nos grandes centros urbanos, normalmente a hora de pico (isto é, intervalo de maior movimento em determinada via) ocorre entre $6 \mathrm{~h}$ e $9 \mathrm{~h} 30$ (período da manhã) e entre $15 \mathrm{~h}$ e $18 \mathrm{~h}$ (período da tarde), entre terça e quinta-feira (Gomes, 2004). Nesses horários, a comunidade local da cidade de Fortaleza realiza frequentemente suas atividades físicas. Em geral, o monitoramento ocorreu durante 144 min para cada período do dia (manhã e tarde), em horários de intenso uso dos AUDs, totalizando 13 semanas de monitoramento nessas regiões da cidade de Fortaleza.

\section{Resultados e discussão}

\section{Cenários meteorológicos}

As principais variáveis meteorológicas foram determinadas durante o monitoramento das espécies de $\mathrm{NO}_{2}, \mathrm{NH}_{3}, \mathrm{SO}_{2}$ e $\mathrm{H}_{2} \mathrm{~S}$ presentes na atmosfera dos AUDs avaliados e estão dispostas na Figura 3.

As temperaturas médias nos AUDs monitorados variaram entre $27,7^{\circ} \mathrm{C}$ (AUD 5) e $31,8{ }^{\circ} \mathrm{C}$ (AUD 4), com amplitude média de $4,1^{\circ} \mathrm{C}$. Já a umidade relativa do ar apresentou médias entre $57,2 \%$ (AUD 2) e 73,3\% (AUD 5), apresentando similaridade com o observado por Lima (2015), para esse mesmo período do ano, em 2014. Observa-se que, no AUD 5, encontraram-se a maior umidade relativa e a menor temperatura média $\left(27,7^{\circ} \mathrm{C}\right)$ para o período estudado, o que pode ser influenciado pela elevada densidade arbórea de médio e grande porte, se comparado aos demais locais monitorados (Manes et al., 2008; Fu et al., 2013; Mohamed \& Othman, 2012). Áreas com representativa presença de espécies arbóreas apresentam menores temperaturas por causa da diminuição da incidência direta solar no local, propiciada com o aumento da evapotranspiração por parte das árvores, favorecendo o microclima local (Marinho et al., 2006).

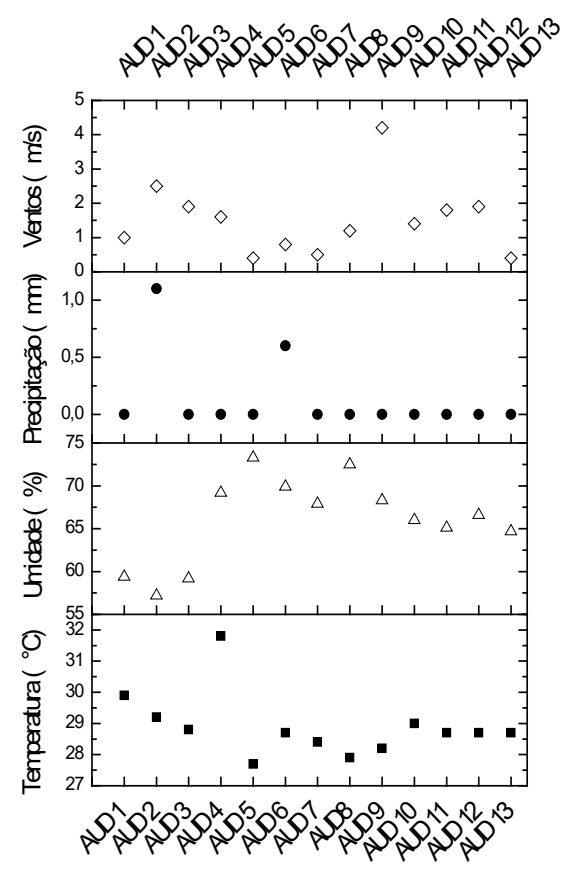

Figura 3 - Principais variáveis meteorológicas medidas durante o monitoramento nos AUDs. Fonte: Autor (2016). 
É importante ressaltar que o período do ano, compreendido durante o presente estudo, é conhecido como seco pela escassez nos níveis de precipitação no semiárido nordestino. Apenas dois locais apresentaram ocorrência de pequenos índices de precipitação durante o estudo, AUD $6(0,6 \mathrm{~mm}) \mathrm{e}$ AUD 2 (1,1 mm). Lima (2015) encontrou valores entre $0,6 \mathrm{~mm}$ e $51,9 \mathrm{~mm}$ durante o período chuvoso em 2014 na cidade de Fortaleza.

As velocidades médias dos ventos apresentaram variações entre 0,4 m/s (AUD 5) e 4,2 m/s (AUD 9). 0 segundo semestre é conhecido como "temporada dos ventos" no Estado do Ceará, principalmente na cidade de Fortaleza, que é uma cidade litorânea margeada pelo Oceano Atlântico. 0 fenômeno é provocado pelo sistema de alta pressão do Atlântico, favorecendo ventos com velocidades superiores às do primeiro semestre do ano (FUNCEME, 2015). Os ventos desempenham importante papel em ações de regulação da qualidade do ar local, pois essa variável da dinâmica climática é uma das responsáveis pela dispersão de compostos poluentes para outras regiões. Os ventos podem transportar poluentes atmosféricos a curtas ou longas distâncias, favorecendo o processo de dispersão dos gases e das partículas do ar (Moraes, 2004). Com exceção do AUD 6 (sudoeste) e do AUD 7 (noroeste), os ventos observados eram predominantemente advindos de nordeste, leste e sudeste, que é característico no litoral cearense (Leite \& Frota, 2010; Azevedo, 2014; Alves et al., 2017). Silva (2010) comenta as influências ocasionadas pelas edificações na intensidade dos ventos, uma vez que Fortaleza é um centro urbano que apresenta uma área repleta de edificações de diversas alturas, variando de acordo com a região da cidade, culminando com possíveis alterações de intensidade e direção dos ventos. Dessa forma, o AUD 6 e o AUD 7 podem ter sofrido forte influência da elevada densidade de edifícios residenciais e comerciais em seu entorno.

\section{Concentrações médias de polventes nos AUDs}

Os AUDs monitorados neste estudo apresentaram considerável variação nas concentrações dos gases traços de $\mathrm{NO}_{2}, \mathrm{NH}_{3}, \mathrm{SO}_{2}$ e $\mathrm{H}_{2} \mathrm{~S}$. A Figura 4 apresenta os perfis médios de concentrações dos poluentes citados neste estudo, bem como os parâmetros de qualidade do ar, reportados por alguns órgãos ambientais no Brasil e no mundo.

De modo geral, as concentrações de $\mathrm{NO}_{2}$ ficaram consideravelmente abaixo dos limites estabelecidos pelo CONAMA ( $190 \mu \mathrm{g} / \mathrm{m}^{3}$ para o padrão secundário), bem como dos limites ilustrados na Figura 4a.

Os valores variaram entre 2,28 e $20,33 \mu \mathrm{g} / \mathrm{m}^{3}$, com menor média no AUD $10\left(2,58 \mu \mathrm{g} / \mathrm{m}^{3}\right)$ e maior média no AUD $13\left(18,48 \mu \mathrm{g} / \mathrm{m}^{3}\right)$. O AUD 10 possui vias com fluxo veicular diário médio muito pequeno (CTAFOR, 2015), o que pode ter contribuído para índices de emissão de $\mathrm{NO}_{2}$ baixos. Reações fotoquímicas envolvendo $\mathrm{NO}_{\mathrm{x}}$ (isto é, emitidos pela exaustão veicular) e outros compostos presentes no ar podem produzir compostos secundários mais reativos ou mais tóxicos do que seus precursores (levar à formação do smog fotoquímico e de chuvas ácidas) (Campos et al., 2010; Chong et al., 2016). Por outro lado, o AUD 13 apresentou a maior concentração média por estar localizado em uma avenida com um volume de tráfego veicular altíssimo, mais de 43 mil veículos/dia, com 58 linhas de transporte coletivo, o que pode ter ocasionado a elevada concentração desse poluente nesse ambiente (Silva, 2010). 
(a)

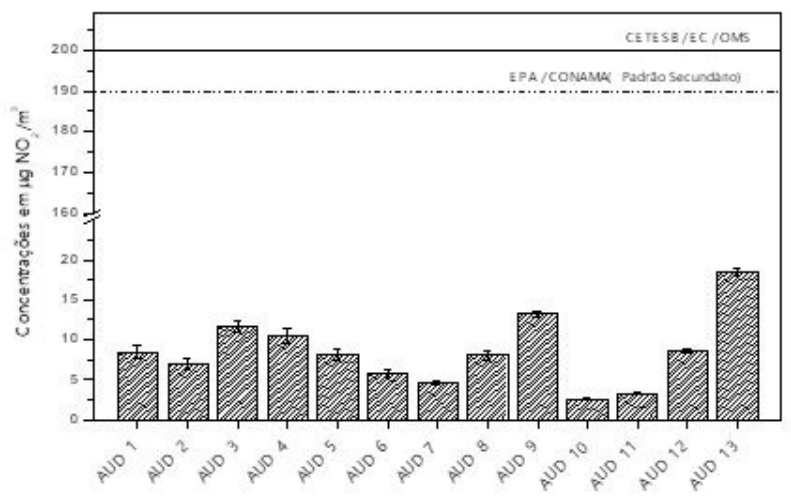

(c)

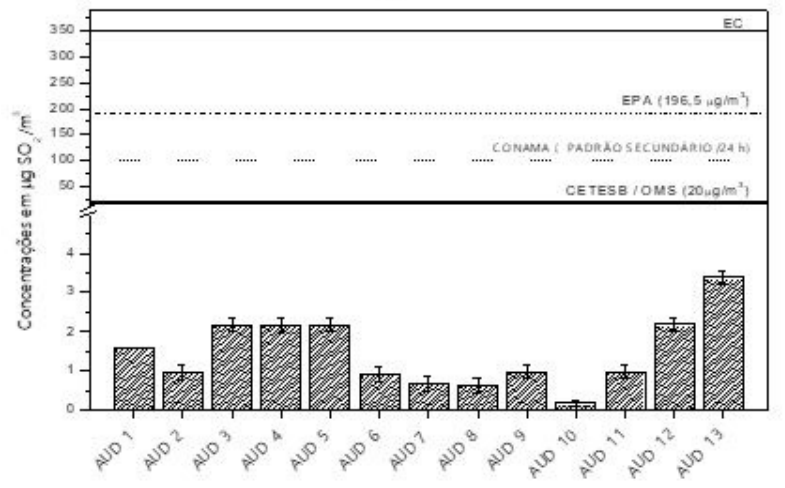

(b)

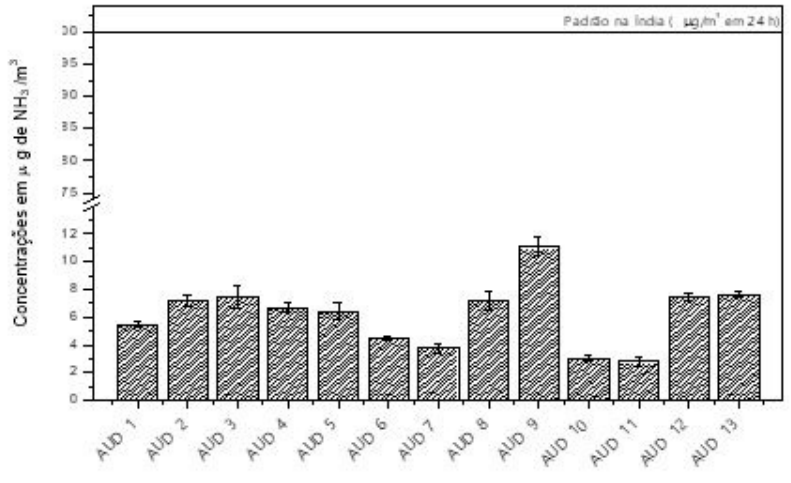

(d)

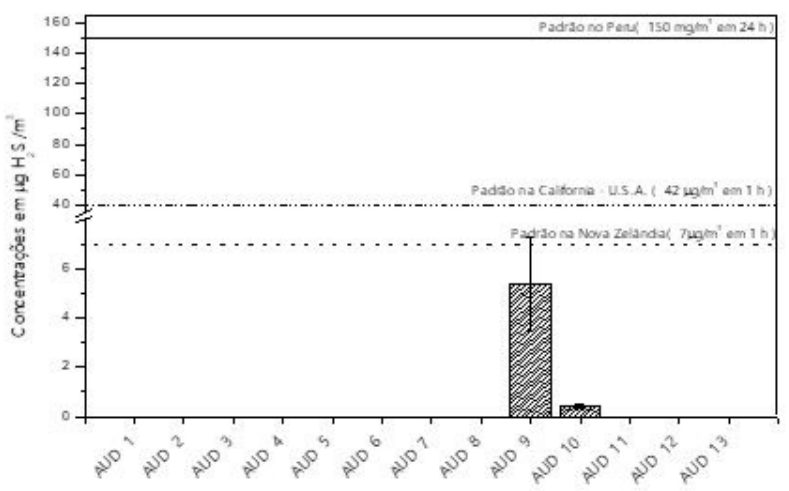

Figura 4 - Concentrações médias dos polventes monitorados por AUD: (a) $\mathrm{NO}_{2}$; (b) $\mathrm{NH}_{3}$; (c) $\mathrm{SO}_{2} ; \mathrm{e}$ (d) $\mathrm{H}_{2} \mathrm{~S}$. Fonte: Autor (2017).

Esses valores são similares aos encontrados na literatura, como no estudo de Lima (2015), também em Fortaleza, no qual as concentrações de $\mathrm{NO}_{2}$ variaram de 9,62 a 19,18 $\mu \mathrm{g} / \mathrm{m}^{3} \mathrm{em}$ uma via urbana de volume de tráfego considerado. Já em Manaus, Marinho et al. (2006) encontraram valores de $\mathrm{NO}_{2}$ entre 3,89 e $22,6 \mu \mathrm{g} / \mathrm{m}^{3}$, sendo os maiores valores encontrados em locais de grande fluxo veicular. Nas cidades de Salvador, Ji-Paraná e Curitiba, concentrações traços de $\mathrm{NO}_{2}$ foram de 3,6 a $12 \mu \mathrm{g} / \mathrm{m}^{3}$, de $4,6 \mu \mathrm{g} / \mathrm{m}^{3}$ e de 6,7 a $11 \mu \mathrm{g} / \mathrm{m}^{3}$, respectivamente (Campos et al., 2010). No âmbito internacional, Bari et al. (2015) encontraram 4,01 $\mu \mathrm{g} / \mathrm{m}^{3}$ de $\mathrm{NO}_{2}$ em Alberta, no Canadá, enquanto Civan et al. (2015) aferiram médias de $7 \mu \mathrm{g} / \mathrm{m}^{3}$ em áreas residenciais e em rodovias na Turquia.

As concentrações de amônia $\left(\mathrm{NH}_{3}\right)$ variaram entre 2,76 e $14,55 \mu \mathrm{g} / \mathrm{m}^{3}$, com concentrações médias no AUD $11 \mathrm{de} 2,78 \mu \mathrm{g} / \mathrm{m}^{3}$ e no AUD 9 de 11,07 $\mu \mathrm{g} / \mathrm{m}^{3}$. O AUD 11 também não está localizado em avenida nem próximo a fontes biológicas, estação de tratamento de esgoto e/ou resíduos sólidos, possíveis emissores desse gás poluente. Entretanto, o AUD 9 apresentou maiores valores de concentrações de $\mathrm{NH}_{3}$ (Figura 4b), o que pode ter ocorrido por causa de sua localização em avenida bastante movimentada (mais de 20 mil veículos/dia) (CTAFOR, 2015; Policarpo et al., 2018) e por estar perto de uma estação de pré-condicionamento de esgoto, que, segundo a literatura, é uma das principais fontes de $\mathrm{NH}_{3}$ em ambientes urbanos, além do tráfego de veículos, das fontes biológicas e das indústrias (Reche et al., 2015). Adicionalmente, com a adoção do sistema de Redução Catalítica Seletiva (RCS-NO ${ }_{\mathrm{x}}$ ), desde janeiro de 2012 no Brasil os veículos pesados a diesel (caminhões e ônibus) utilizam uma solução a base de ureia como agente redutor (Arla 32) de $\mathrm{NO}_{\mathrm{x}}$ no sistema pós-combustão - nesse caso, esses sistemas também podem agir como emissor de $\mathrm{NH}_{3}$, podendo haver a liberação da chamada $\mathrm{NH}_{3}$ slip (amônia de fuga não reagente) para a atmosfera (Sheppard et al., 2011; Van den Bossche et al., 2015; Reche et al., 2015). Valores similares de $\mathrm{NH}_{3}$ também foram encontrados por Reche et al. (2015) 
para a cidade de Barcelona, na Espanha, utilizando monitoramento passivo. Lima (2015) encontrou em Fortaleza concentrações máximas de $4,89 \mu \mathrm{g} / \mathrm{m}^{3}$. É de salientar que o autor registrou velocidades dos ventos variando entre 3,6 e $5,7 \mathrm{~m} / \mathrm{s}$ (outubro, 2014), enquanto, no presente estudo, a velocidade média foi de $0,4 \mathrm{~m} / \mathrm{s}$, o que também pode ter influenciado nas concentrações de $\mathrm{NO}_{2}$ e $\mathrm{SO}_{2}$, como reportado por Zbieranowski \& Aherne (2012).

Em relação ao dióxido de enxofre $\left(\mathrm{SO}_{2}\right)$, foram obtidas concentrações máximas de $3,98 \mu \mathrm{g} / \mathrm{m}^{3}$, com menor média no AUD $10\left(0,18 \mu \mathrm{g} / \mathrm{m}^{3}\right)$ e maior média no AUD $13\left(3,36 \mu \mathrm{g} / \mathrm{m}^{3}\right)$, como ilustrado na Figura 4c. Os valores encontrados estão em conformidade com os limites estabelecidos pelo CONAMA (Brasil, 1990), pela European Comunity $\left(350 \mu \mathrm{g} / \mathrm{m}^{3}\right)$ (WHO, 2000) e pela CETESB (2015) $\left(20 \mu \mathrm{g} / \mathrm{m}^{3}\right)$. É de ressaltar que a Resolução CONAMA no 03/1990 foi, recentemente, atualizada para Resolução CONAMA no 491/2018 (Brasil, 2018), similar ao estabelecido pela CETESB (2015). Campos et al. (2010), monitorando as áreas urbanas de Salvador e de Curitiba, encontraram concentrações de 1,8 a $3,9 \mu \mathrm{g} / \mathrm{m}^{3}$ e de 1,2 a $1,9 \mu \mathrm{g} / \mathrm{m}^{3}$, respectivamente - valores bem próximos aos observados no presente estudo. Vale ressaltar que as emissões de $\mathrm{SO}_{2}$ são oriundas, principalmente, dos veículos automotores a diesel e podem ter sido reduzidas em função da Resolução no 50 (23/12/2013) da Agência Nacional do Petróleo (ANP), que determinou uma redução no teor de enxofre no diesel S10 (10 ppm de S) e $S 50$ (50 ppm de S) a partir de 2014.

Quanto ao sulfeto de hidrogênio $\left(\mathrm{H}_{2} \mathrm{~S}\right)$, ele foi detectado apenas nos AUDs 9 e 10 (Figura 4d). As concentrações variaram entre 0,50 e $26,63 \mu \mathrm{g} / \mathrm{m}^{3}$, com menor média no AUD $10\left(0,76 \mu \mathrm{g} / \mathrm{m}^{3}\right)$ e maior média no AUD $9\left(7,53 \mu \mathrm{g} / \mathrm{m}^{3}\right) . \mathrm{O} \mathrm{H}_{2} \mathrm{~S}$ é um gás que apresenta odor repugnante, com limiar de percepção de $0,70 \mu \mathrm{g} / \mathrm{m}^{3}$. É normalmente gerado com a amônia em processos industriais (indústria de alimentos, pecuária, fabricação de couro e tratamento de esgotos) (Chung et al., 2001) e em processos naturais (campos petrolíferos, águas subterrâneas, zonas pantanosas ou de mangue, jazidas de sal e carvão, minérios sulfetados e erupção de vulcões) (Campos et al., 2010). Nas estações de tratamento de esgoto, $\mathrm{o} \mathrm{H}_{2} \mathrm{~S}$ pode ser gerado durante a decomposição anaeróbia da matéria orgânica.

O AUD 9 possui em seu entorno uma das maiores estações de pré-condicionamento de esgoto de Fortaleza, enquanto o AUD 10 está localizado próximo a um córrego bastante poluído com liberação de odores. Essas características podem contribuir para a presença de $\mathrm{H}_{2} \mathrm{~S}$ nesses ambientes. Concentrações similares dessa espécie também foram reportadas na literatura em outras localidades, como Grasel (2014), que determinou de 0,14 a $32 \mu \mathrm{g} / \mathrm{m}^{3} \mathrm{de}_{2} \mathrm{~S}$ na cidade de Curitiba. Delgado et al. (1999) encontraram concentrações entre 1 e $8 \mu \mathrm{g} / \mathrm{m}^{3}$ em Tenerife, na Espanha, enquanto Kim et al. (2013) registraram concentrações entre 5 e $60 \mu \mathrm{g} / \mathrm{m}^{3}$ na Coreia do Sul. A presença de $\mathrm{H}_{2} \mathrm{~S}$ no ar causa incômodo nas vizinhanças das estações de tratamento de esgoto, podendo provocar danos à saúde (Grasel, 2014). Segundo a USEPA (2003), em situações de superexposição em ambientes ocupacionais, concentrações acima de $2 \mu \mathrm{g} / \mathrm{m}^{3}$ no ar podem causam efeitos adversos na saúde humana. De acordo com WHO (2000), concentrações de $\mathrm{H}_{2} \mathrm{~S}$ entre 10 e $30 \mu \mathrm{g} / \mathrm{m}^{3}$ no ar podem ocasionar dores de cabeça e irritação nos olhos e no sistema respiratório. Dessa forma, é de fundamental importância estudos como este, sobretudo o contínuo monitoramento em locais passíveis à emissão dessa espécie poluente, uma vez que ela é severamente nociva à saúde humana (Campos et al., 2010; USEPA, 2003). A Figura 5 apresenta as concentrações de $\mathrm{NO}_{2}, \mathrm{NH}_{3}$ e $\mathrm{H}_{2} \mathrm{~S}$ aos sábados, bem como os limites impostos pelas respectivas legislações anteriormente citadas, tanto nacionais quanto internacionais. 
(a)

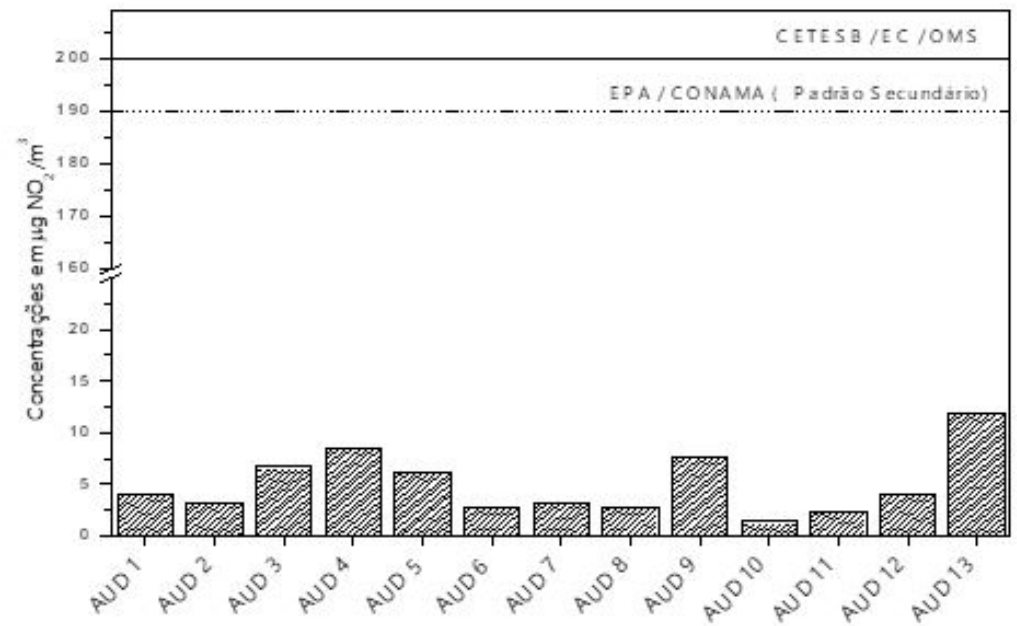

(b)

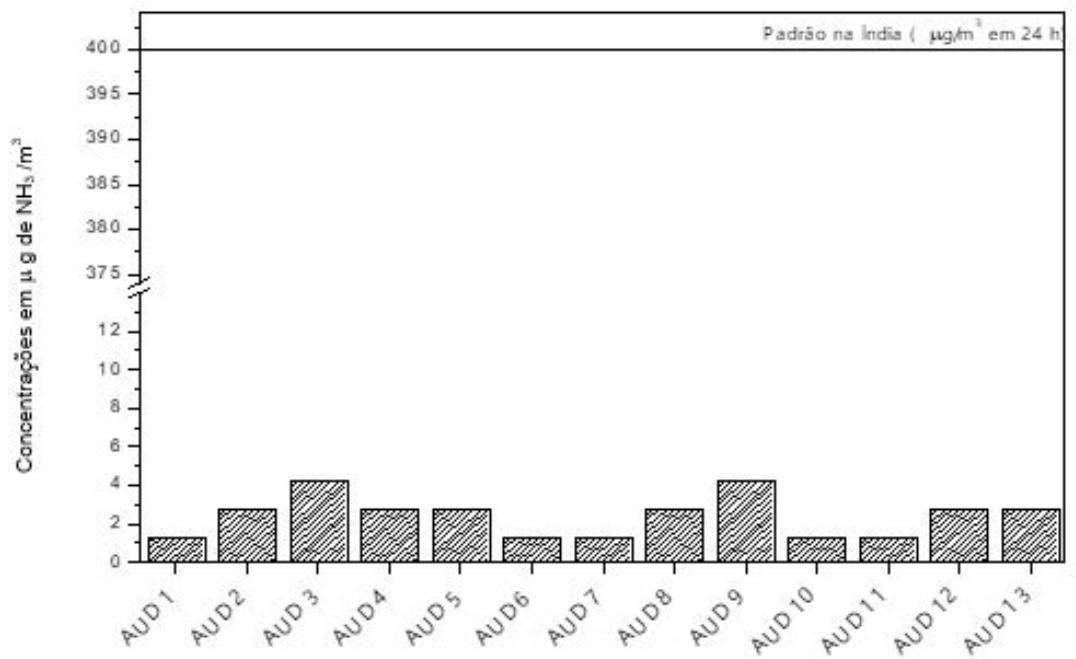

(c)

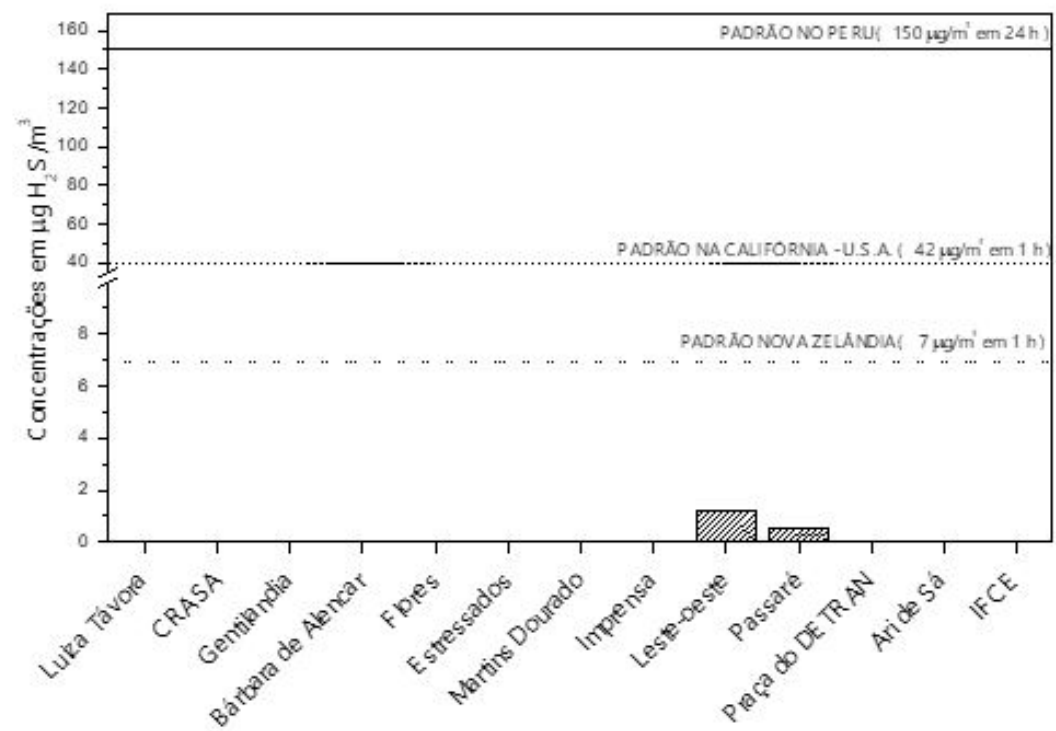

Figura 5 - Concentrações de polventes monitorados aos sábados por AUD em Fortaleza: (a) NO 2 ; (b) $\mathrm{NH}_{3}$; e (c) $\mathrm{H}_{2} \mathrm{~S}$. Fonte: Autor (2017). 
Observa-se que as concentrações de $\mathrm{NO}_{2}, \mathrm{NH}_{3}$ e $\mathrm{H}_{2} \mathrm{~S}$ aos sábados (elucidando um fim de semana) foram bem menores do que as encontradas durante os dias úteis, nos respectivos AUDs. A provável causa da redução das emissões está relacionada com a diminuição do fluxo veicular, em comparação com os dias úteis (Azevedo, 2014). Dessa forma, a concentração de $\mathrm{NO}_{2}$ foi maior no AUD 13 (IFCE) $\left(11,9 \mu \mathrm{g} / \mathrm{m}^{3}\right)$ e menor no AUD 10 (Praça Farias Brito) $\left(1,4 \mu \mathrm{g} / \mathrm{m}^{3}\right)$ (ver Figura 5a). Já a amônia também apresentou maior concentração no AUD 9 (Leste-oeste) $\left(4,23 \mu \mathrm{g} / \mathrm{m}^{3}\right)$, condizente com o observado nas médias semanais. A menor concentração registrada no sábado $\left(1,30 \mu \mathrm{g} / \mathrm{m}^{3}\right)$ se deu no AUD 7 (Praça Martins Dourado), local situado em ambiente residencial com baixo fluxo de veículos e sem fontes emissoras por decomposição bacteriana (Figura 5b).

Quanto ao $\mathrm{H}_{2} \mathrm{~S}$, a presença desse poluente só foi detectada também nos AUD 9 e 10, como observado nos dias da semana. A maior concentração foi no AUD 9 (Leste-oeste) $\left(1,23 \mu \mathrm{g} / \mathrm{m}^{3}\right)$, e a menor, no AUD 10 (Praça Farias Brito) $\left(0,55 \mu \mathrm{g} / \mathrm{m}^{3}\right)$. Dessa maneira, a presença de $\mathrm{H}_{2} \mathrm{~S}$ nesses mesmos locais aos sábados reitera as explicações dadas quanto à presença de sorvedouros desse poluente nos ambientes monitorados, como a estação de tratamento de esgoto no AUD 9 e o córrego poluído no AUD 10 (Figura 5c).

Por fim, a Tabela 1 apresenta uma síntese comparativa entre as concentrações das espécies monitoradas dos AUDs na cidade de Fortaleza com os dados encontrados na literatura (Marinho et al., 2006; Campos et al., 2010; Bari et al., 2015). As concentrações das espécies $\mathrm{NO}_{2}, \mathrm{NH}_{3}, \mathrm{SO}_{2}$ e $\mathrm{H}_{2} \mathrm{~S}$ possuem similaridades em outros locais no Brasil e no mundo, demonstrando a presença dessas espécies em ambientes urbanos (Oliveira et al., 2011). É de salientar a importância do monitoramento como uma ferramenta de controle de poluentes atmosféricos, sobretudo em ambientes urbanos utilizados para a prática de atividade física ao ar livre, podendo subsidiar ações de gestão de emissões atmosféricas.

Tabela 1 - Comparação entre concentrações médias dos polventes estudados e resultados da literatura

\begin{tabular}{cccccc}
\hline \multirow{2}{*}{ Locais monitorados } & \multicolumn{3}{c}{ Polventes atmosféricos $\left[\mathbf{\mu g} / \mathbf{m}^{3}\right]$} & & \multirow{2}{*}{ Referências } \\
\cline { 2 - 5 } & $\mathbf{N O}_{2}$ & $\mathbf{S O}_{2}$ & $\mathbf{N H}_{3}$ & $\mathbf{H}_{2} \mathbf{S}$ & \\
\hline Fortaleza - Brasil & 8,5 & 1,5 & 6,2 & 4,1 & Este trabalho \\
Alberta - Canadá & 4,0 & 1,3 & - & - & Bari et al. (2015) \\
Salvador - Brasil & 7,8 & 2,9 & - & - & Campos et al. (2010) \\
Curitiba - Brasil & 8,9 & 1,6 & - & 16,1 & Campos et al. (2010), Grasel \\
Manaus - Brasil & 13,5 & - & - & - & $(2014)$ \\
Barcelona - Espanha & - & - & 6,9 & - & Marinho et al. (2006) \\
Canadá (urbano e rural) & - & - & $2,0-4,2$ & - & Reche et al. (2015) \\
Coreia do Sul & - & - & - & 32,5 & Zbieranowski \& Aherne (2012) \\
\hline
\end{tabular}

Fonte: Autor (2017).

\section{Conclusão}

As concentrações dos poluentes atmosféricos do tipo $\mathrm{SO}_{2}, \mathrm{NO}_{2}, \mathrm{NH}_{3}$, e $\mathrm{H}_{2} \mathrm{~S}$ em alguns Ambientes Urbanos Desportivos da cidade de Fortaleza mostraram-se dentro dos limites estabelecidos pela legislação CONAMA no 03/1990 (NO e $\mathrm{SO}_{2}$ ), assim como pela CETESB, pela USEPA (United States Environmental Protection Agency), pela EC (European Comunity) e pela OMS (Organização Mundial de Saúde). As emissões desses poluentes estão diretamente relacionadas ao fluxo de veículos nas proximidades dos ambientes monitorados. As maiores concentrações de $\mathrm{NH}_{3}$ e $\mathrm{H}_{2} \mathrm{~S}$ foram observadas na AUD 9 (localidade à beira-mar), nas proximidades de uma das maiores estações de pré-condicionamento de esgoto do município de Fortaleza. Os AUDs monitorados no presente estudo se encontram em boas condições de uso, como equipamentos públicos para o desenvolvimento de atividades físicas pela população da cidade de Fortaleza, com índice de qualidade do ar considerado bom. No entanto, novos estudos e o desenvolvimento de uma rede de monitoramento de qualidade do ar na região são necessários para que possam subsidiar políticas públicas de qualidade do ar, ainda incipientes no Brasil e, principalmente, no Ceará. 


\section{Referências}

Alves, J. M. B., Silva, E. M., Sombra, S. S., Barbosa, A. C. B., Santos, A. C. S., \& Lira, M. A. T. (2017). Eventos extremos diários de chuva no nordeste do Brasil e características atmosféricas. Revista Brasileira de Meteorologia, 32(2), 227-233. http://dx.doi.org/10.1590/0102-77863220012.

Azevedo, J. A. H. (2014). Monitoramento atmosférico de material particulado, metais pesados e hidrocarbonetos policíclicos aromáticos em um trecho urbano da cidade de Fortaleza (Dissertação de mestrado). Instituto Federal do Ceará, Fortaleza.

Bari, M. A., Curran, R. L. T., \& Kindzierski, W. B. (2015). Field performance evaluation of Maxxam passive samplers for regional monitoring of ambient $\mathrm{SO}_{2}, \mathrm{NO}_{2}$ and $\mathrm{O}_{3}$ concentrations in Alberta, Canada. Atmospheric Environment, 114, 39-47. http://dx.doi.org/10.1016/j.atmosenv.2015.05.031.

Batista, F. L. R., Almeida, M. I., Therrien, S. M. N., Sousa, J. M., Pequeno, L. L., \& Duavy, L. M. (2005). Políticas públicas de saúde em Fortaleza: do movimento pela reforma sanitária à reforma administrativa. O Público e o Privado, 6, 19 -34.

Brasil. Ministério do Meio Ambiente - MMA. Conselho Nacional do Meio Ambiente - CONAMA. (1990, 22 de agosto). Resolução CONAMA no 3, de 28 de junho de 1990. Dispõe sobre padrões de qualidade do ar, previstos no PRONAR. Brasília: Diário Oficial da União, seção 1. Recuperado em 12 de dezembro de 2017, de http://www.mma.gov.br/port/conama/legiabre.cfm?codlegi=100

Brasil. Ministério do Meio Ambiente - MMA. Conselho Nacional do Meio Ambiente - CONAMA. (2018). Resolução no 491, de 19 de novembro de 2018. Dispõe sobre padrões de qualidade do ar. Brasília: Diário Oficial da União. Recuperado em 7 de abril de 2019, de http://www2.mma.gov.br/port/conama/legiabre.cfm?codlegi=740

Campos, V. P., Cruz, L. P. S., Godoi, R. H. M., Godoi, A. F. L., \& Tavares, T. M. (2010). Development and validation of passive samplers for atmospheric monitoring of $\mathrm{SO}_{2}, \mathrm{NO}_{2}, \mathrm{O}_{3}$ and $\mathrm{H}_{2} \mathrm{~S}$ in tropical areas. Microchemical Journal, 96(1), 132-138. http://dx.doi.org/10.1016/j.microc.2010.02.015.

Cárdenas Rodríguez, M., Dupont-Courtade, L., \& Oueslati, W. (2016). Air pollution and urban structure linkages: evidence from European cities. Renewable \& Sustainable Energy Reviews, 53, 1-9.

http://dx.doi.org/10.1016/j.rser.2015.07.190.

Centro de Tráfego em Área de Fortaleza - CTAFOR. (2015). Dados internos do Controle de Tráfego em Área de Fortaleza. Fortaleza. Recuperado em 20 de dezembro de 2015, de http://www.fortaleza.ce.gov.br/amc/ctafor

Civan, M. Y., Elbir, T., Seyfioglu, R., Kuntasal, Ö. O., Bayram, A., Doğan, G., Yurdakul, S., Andiç, Ö., Müezzinoğlu, A., Sofuoglu, S. C., Pekey, H., Pekey, B., Bozlaker, A., Odabasi, M., \& Tuncel, G. (2015). Spatial and temporal variations in atmospheric VOCs, $\mathrm{NO}_{2}, \mathrm{SO}_{2}$, and $\mathrm{O}_{3}$ concentrations at a heavily industrialized region in Western Turkey, and assessment of the carcinogenic risk levels of benzene. Atmospheric Environment, 103, 102-113.

http://dx.doi.org/10.1016/j.atmosenv.2014.12.031.

Companhia Ambiental do Estado de São Paulo - CETESB. (2014). Padrões de qualidade do ar. São Paulo. Recuperado em 15 de fevereiro de 2016, de http://www.cetesb.sp.gov.br/ar/Informa?es-B?sicas/22-Padr?es-e?ndices

Companhia Ambiental do Estado de São Paulo - CETESB. (2015). Padrões de qualidade do ar. São Paulo. Recuperado em 6 de abril de 2019, de https://cetesb.sp.gov.br/wp-content/uploads/2017/09/relatorio-ar2016.pdf

COP21. (2015). United Nations Conference on Climate Change. Paris. Recuperado em 3 de março de 2018, de http://www.cop21paris.org/

Costa, L. A., Osborne, R., Santos, R. F., \& Ribeiro, C. H. V. (2015). Sports urban intervention: an ethnographic study about the Rhizome group. Revista Brasileira de Educação Física e Esporte, 29(1), 81-93.

http://dx.doi.org/10.1590/1807-55092015000100081.

Checa Vizcaíno, M. A., González-Comadran, M., \& Jacquemin, B. (2016). Outdoor air pollution and human infertility: a systematic review. Fertility and Sterility, 106(4), 897-904. http://dx.doi.org/10.1016/j.fertnstert.2016.07.1110. PMid:27513553.

Chong, J., Kim, Y. J., Gu, M., Wagner, T., \& Song, C. H. (2016). Mobile MAX-DOAS observation of $\mathrm{NO}_{2}$ and comparison with OMI satellite data in the western coastal areas of the Korean peninsula. Chemosphere, 143, 10-16. http://dx.doi.org/10.1016/j.chemosphere.2015.06.071. PMid:26239513. 
Chung, Y., Huang, C., \& Tseng, C. (2001). Biological elimination of $\mathrm{H}_{2} \mathrm{~S}$ and $\mathrm{NH}_{3}$ from waste gases by biofilter packed with immobilized heterotrophic bacteria. Chemosphere, 43(8), 1043-1050. http://dx.doi.org/10.1016/S00456535(00)00211-3. PMid:11368219.

Dahmann, N., Wolch, J., Joassart-Marcelli, P., Reynolds, K., \& Jerrett, M. (2010). The active city? Disparities in provision of urban public recreation resources. Health \& Place, 16(3), 431-445. http://dx.doi.org/10.1016/j.healthplace.2009.11.005. PMid:20056472.

Davis Instruments. (2015). Recuperado em 11 de janeiro de 2015, de http://www.davisnet.com/solution/vantage-vue/ Day, D. E., Chen, X., Gebhart, K. A., Carrico, C. M., Schwandner, F. M., Benedict, K. B., Schichtel, B. A., \& Collett, J. L., Jr. (2012). Spatial and temporal variability of ammonia and other inorganic aerosol species. Atmospheric Environment, 61, 490-498. http://dx.doi.org/10.1016/j.atmosenv.2012.06.045.

Delgado, S., Alvarez, M., Rodriguez-Gomez, L. E., \& Aguiar, E. (1999). $\mathrm{H}_{2}$ S generation in a reclaimed urban wastewater pipe. Case study: Tenerife (Spain). Water Research, 33(2), 539-547. http://dx.doi.org/10.1016/S00431354(98)00223-1.

Departamento Estadual de Trânsito do Estado do Ceará - DETRAN-CE. (2017). Quantidade de veículo por município. Fortaleza. Recuperado em 4 de fevereiro de 2018, de

http://www.detran.ce.gov.br/site/arquivos/estatisticas/Ve\%C3\%ADculos/2016/VEICULOS\%20POR\%20MUNICI PIOS\%20-20AT\%C3\%89\%20DEZEMBRO\%202016.pdf

Eime, R. M., Sawyer, N., Harvey, J. T., Casey, M. M., Westerbeek, H., \& Payne, W. R. (2015). Integrating public health and sport management: sport participation trends 2001-2010. Sport Management Review, 18(2), 207-217. http://dx.doi.org/10.1016/j.smr.2014.05.004.

European Respiratory Society and European Lung Foundation - ERS\&ELF. (2015). Exercise and air quality: 10 top tips. Breathe, 11(3), 239-242. http://dx.doi.org/10.1183/20734735.ELF113. PMid:26634008.

Fu, X., Wang, S., Zhao, B., Xing, J., Cheng, Z., Liu, H., \& Hao, J. (2013). Emission inventory of primary pollutants and chemical speciation in 2010 for the Yangtze River Delta region, China. Atmospheric Environment, 70, 39-50. http://dx.doi.org/10.1016/j.atmosenv.2012.12.034.

Fundação Cearense de Meteorologia e Recursos Hídricos - FUNCEME. (2015). Recuperado em 14 de janeiro de 2015, de http://www.funceme.br/index.php/areas/

Gomes, M. J. T. L. (2004). Volume horário de projeto para rodovias estaduais do Ceará: análise e contribuição (Dissertação de mestrado). Universidade Federal do Ceará, Fortaleza.

Grasel, A. M. (2014). Determinação de sulfeto de hidrogênio nas proximidades de estações de tratamento de esgoto em Curitiba-PR, Brasil (Dissertação de mestrado). Universidade Federal do Paraná, Curitiba.

Instituto Brasileiro de Geografia e Estatística - IBGE. (2016). Cidades: população. Recuperado em 20 setembro de 2017, de http://www.cidades.ibge.gov.br/v3/cidades/municipio/2304400

Kim, K. H., Jo, S. H., Song, H. C., Pandey, S. K., Song, H. N., Oh, J. M., Sunwoo, Y., \& Choi, K. C. (2013). Diagnostic analysis of offensive odorants in a large municipal waste treatment plant in an urban area. International Journal of Environmental Science and Technology, 10(2), 261-274. http://dx.doi.org/10.1007/s13762-012-0134-7.

Kourtidis, K., Kelesis, A., \& Petrakakis, M. (2008). Hydrogen sulfide $\left(\mathrm{H}_{2} \mathrm{~S}\right)$ in urban ambient air. Atmospheric Environment, 42(32), 7476-7482. http://dx.doi.org/10.1016/j.atmosenv.2008.05.066.

Leite, R. C. V., \& Frota, A. B. (2010). Análise da influência da verticalização sobre a ventilação natural através de aplicativo de dinâmica dos fluidos computadorizada: estudo de caso em Fortaleza, Ceará. In Anais do VIII Seminário Internacional de Arquitetura, Urbanismo e Design. São Paulo: Universidade de São Paulo.

Li, R., Warneke, C., Graus, M., Field, R., Geiger, F., Veres, P. R., Soltis, J., Li, S.-M., Murphy, S. M., Sweeney, C., Pétron, G., Roberts, J. M., \& Gouw, J. (2014). Measurements of hydrogen sulfide (H2S) using PTR-MS: calibration, humidity dependence, inter-comparison and results from field studies in an oil and gas production region. Atmospheric Measurement Techniques, 7(10), 3597-3610. http://dx.doi.org/10.5194/amt-7-3597-2014.

Lima, R. M. (2015). Avaliação da qualidade do ar em um trecho urbano da cidade de Fortaleza - Ceará (Dissertação de mestrado). Instituto Federal do Ceará, Fortaleza.

Liu, Y. L., Ge, Y. E., \& Gao, H. O. (2014). Improving estimates of transportation emissions: modeling hourly truck traffic using period-based car volume data. Transportation Research Part D, Transport and Environment, 26, 32-41. http://dx.doi.org/10.1016/j.trd.2013.10.007. 
Lodge, J. P., Jr. (1989). Methods of air sampling and analysis (3rd ed.). New York: Intersociety Committee.

Manes, F., Salvatori, E., La Torre, G., Villari, P., Vitale, M., Biscontini, D., \& Incerti, G. (2008). Urban green and its relation with air pollution: ecological studies in the Metropolitan area of Rome. Italian Journal of Public Health, 5(4), 278-283.

Marinho, N. S., Novaes, J. A. P., \& Sargentini, E., Jr. (2006). Levantamento da distribuição e dos níveis de concentração de $\mathrm{NO}_{2}$ na Cidade de Manaus por amostragem passiva. In Anais do XLVI Congresso Brasileiro de Química. Salvador: Associação Brasileira de Química Regional Bahia.

Mitra, A. P., Morawska, L., Sharma, C., \& Zhang, J. (2002). Chapter two: methodologies for characterization of combustion sources and for quantification of their emissions. Chemosphere, 49(9), 903-922. http://dx.doi.org/10.1016/S0045-6535(02)00236-9. PMid:12492157.

Mohamed, N., \& Othman, N. (2012). Determining the visitors satisfactions at urban recreational area. Procedia: Social and Behavioral Sciences, 49, 175-182. http://dx.doi.org/10.1016/j.sbspro.2012.07.016.

Moraes, M. R. (2004). Ferramenta para a previsão de vento e dispersão de poluentes na micro-escala atmosférica (Tese de doutorado). Universidade Federal de Santa Catarina, Florianópolis.

Muezzinoglu, A. (2003). A study of volatile organic sulfur emissions causing urban odors. Chemosphere, 51(4), 245252. http://dx.doi.org/10.1016/S0045-6535(02)00821-4. PMid:12604076.

Oliveira, M. L. M., Silva, C. M., Moreno-Tost, R., Farias, T. L., Jiménez-López, A., \& Rodríguez-Castellón, E. (2011). Modelling of NOx emission factors from heavy and light-duty vehicles equipped with advanced aftertreatment systems. Energy Conversion and Management, 52(8-9), 2945-2951.

http://dx.doi.org/10.1016/j.enconman.2011.02.025.

Papamanolis, N. (2015). The main characteristics of the urban climate and the air quality in Greek cities. Urban Climate, 12, 49-64. http://dx.doi.org/10.1016/j.uclim.2014.11.003.

Policarpo, N. A., Silva, C., Lopes, T. F. A., Araújo, R. S., Cavalcante, F. S. Á., Pitombo, C. S., \& Oliveira, M. L. M. (2018). Road vehicle emission inventory of a Brazilian metropolitan area and insights for other emerging economies. Transportation Research Part D, Transport and Environment, 58, 172-185.

http://dx.doi.org/10.1016/j.trd.2017.12.004.

Reche, C., Viana, M., Karanasiou, A., Cusack, M., Alastuey, A., Artiñano, B., Revuelta, M. A., López-Mahía, P., BlancoHeras, G., Rodríguez, S., Sánchez de la Campa, A. M., Fernández-Camacho, R., González-Castanedo, Y., Mantilla, E., Tang, Y. S., \& Querol, X. (2015). Urban $\mathrm{NH}_{3}$ levels and sources in six major Spanish cities. Chemosphere, 119, 769777. http://dx.doi.org/10.1016/j.chemosphere.2014.07.097. PMid:25194477.

Righi, S., Farina, F., Marinello, S., Andretta, M., Lucialli, P., \& Pollini, E. (2013). Development and evaluation of emission disaggregation models for the spatial distribution of non-industrial combustion atmospheric pollutants. Atmospheric Environment, 79, 85-92. http://dx.doi.org/10.1016/j.atmosenv.2013.06.021.

Roberts, J. D., Voss, J. D., \& Knight, B. (2014). The association of ambient air pollution and physical inactivity in the United States. PLoS One, 9(3), 90-143. http://dx.doi.org/10.1371/journal.pone.0090143. PMid:24598907.

Rundell, K. W. (2012). Effect of air pollution on athlete health and performance. British Journal of Sports Medicine, 46(6), 407-412. http://dx.doi.org/10.1136/bjsports-2011-090823. PMid:22267572.

Sheppard, L. J., Leith, I. D., Mizunuma, T., Neil Cape, J., Crossley, A., Leeson, S., Sutton, M. A., Dijk, N., \& Fowler, D. (2011). Dry deposition of ammonia gas drives species change faster than wet deposition of ammonium ions: evidence from a long-term field manipulation. Global Change Biology, 17(12), 3589-3607.

http://dx.doi.org/10.1111/j.1365-2486.2011.02478.x.

Silva, J. A. (2010). Um estudo da qualidade do ar na cidade de Fortaleza (Dissertação de mestrado). Universidade Estadual do Ceará, Fortaleza.

United States Environmental Protection Agency - USEPA. (1977). Sodium arsenite method for determination of nitrogen dioxide in the atmosphere: EPA designated equivalent method no EQN-1277-026. Research Triangle Park.

United States Environmental Protection Agency - USEPA. (1998). Network design for State and Local Air Monitoring Stations (SLAMS), National Air Monitoring Stations (NAMS), and Photochemical Assessment Monitoring Stations. Research Triangle Park: PAMS.

United States Environmental Protection Agency - USEPA. (2003). EPA-635/R-03/005.U.S.: toxicological review of hydrogen sulfide. Washington: Environmental Protection Agency. 
United States Environmental Protection Agency - USEPA. (2007). Probe siting criteria for ambient air quality monitoring (CFR 40, Chapt. I, Part 58, Appendix E. U.S.). Washington. Recuperado em 10 de janeiro de 2015, de https://www3.epa.gov/ttnamti1/files/ambient/longpath/fropenph.pdf

Urban Leds. (2016). Urban low emissions development strategy project. Recuperado em 20 de fevereiro de 2017, de http://urbanleds.iclei.org/index.php?id=177

Van den Bossche, J., Peters, J., Verwaeren, J., Botteldooren, D., Theunis, J., \& De Baets, B. (2015). Mobile monitoring for mapping spatial variation in urban air quality: development and validation of a methodology based on an extensive dataset. Atmospheric Environment, 105, 148-161. http://dx.doi.org/10.1016/j.atmosenv.2015.01.017.

Vormittag, E. M. P. A. A., Costa, R. R., Braga, A. A., Miranda, M., Nascimento, N. C., \& Saldiva, P. H. N. (2014). Monitoramento da qualidade do ar no Brasil. São Paulo: Instituto Saúde e Sustentabilidade.

Wang, K., \& Zhang, Y. (2014). 3-D agricultural air quality modeling: impacts of $\mathrm{NH}_{3} / \mathrm{H}_{2} \mathrm{~S}$ gas-phase reactions and bidirectional exchange of $\mathrm{NH}_{3}$. Atmospheric Environment, 98, 554-570.

http://dx.doi.org/10.1016/j.atmosenv.2014.09.010.

Wang, S., Nan, J., Shi, C., Fu, Q., Gao, S., Wang, D., Cui, H., Saiz-Lopez, A., \& Zhou, B. (2015). Atmospheric ammonia and its impacts on regional air quality over the megacity of Shanghai, China. Scientific Reports, 5(1), 15842. http://dx.doi.org/10.1038/srep15842. PMid:26514559.

Węziak-Białowolska, D. (2016). Quality of life in cities: empirical evidence in comparative European perspective. Cities, 58, 87-96. http://dx.doi.org/10.1016/j.cities.2016.05.016.

World Health Organization - WHO. (1981). Environmental health criteria 19: hydrogen sulfide. Geneva.

World Health Organization - WHO. (2000). Air quality guideline for Europe (2nd ed., European Series, No. 91). Copenhagen: WHO Regional Publications.

World Health Organization - WHO. (2010). Exposure to air pollution: a major public health concern. Geneva. Recuperado em 11 de fevereiro de 2017, de http://www.who.int/ipcs/features/air_pollution.pdf?ua=1

Zbieranowski, A. L., \& Aherne, J. (2012). Spatial and temporal concentration of ambient atmospheric ammonia in southern Ontario, Canada. Atmospheric Environment, 62, 441-450.

http://dx.doi.org/10.1016/j.atmosenv.2012.08.041.

Editor: Harry Bollmann

Recebido: Mar. 04, 2019

Aprovado: Mar. 19, 2019 